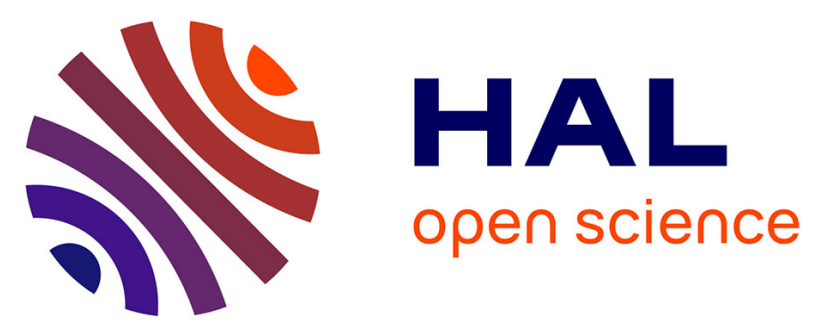

\title{
12-HETE is a regulator of PGE2 production via COX-2 expression induced by a snake venom group IIA phospholipase A2 in isolated peritoneal macrophages
}

Vanessa Moreira, José María Gutiérrez, Bruno Lomonte, Marco Aurélio

Ramirez Vinolo, Rui Curi, Gerard Lambeau, Catarina Teixeira

\section{To cite this version:}

Vanessa Moreira, José María Gutiérrez, Bruno Lomonte, Marco Aurélio Ramirez Vinolo, Rui Curi, et al.. 12-HETE is a regulator of PGE2 production via COX-2 expression induced by a snake venom group IIA phospholipase A2 in isolated peritoneal macrophages. Chemico-Biological Interactions, 2020, 317, pp.108903. 10.1016/j.cbi.2019.108903 . hal-03093259v1

\section{HAL Id: hal-03093259 \\ https://hal.science/hal-03093259v1}

Submitted on 3 Jan 2021 (v1), last revised 4 Jan 2021 (v2)

HAL is a multi-disciplinary open access archive for the deposit and dissemination of scientific research documents, whether they are published or not. The documents may come from teaching and research institutions in France or abroad, or from public or private research centers.
L'archive ouverte pluridisciplinaire HAL, est destinée au dépôt et à la diffusion de documents scientifiques de niveau recherche, publiés ou non, émanant des établissements d'enseignement et de recherche français ou étrangers, des laboratoires publics ou privés. 
12-HETE is an important regulator of $\mathrm{PGE}_{2}$ production via COX-2 expression induced by a snake venom group IIA phospholipase $\mathrm{A}_{2}$

Vanessa Moreira $^{\mathrm{a}, *}$, José María Gutiérrez ${ }^{\mathrm{b}}$, Bruno Lomonte ${ }^{\mathrm{b}}$, Marco Aurélio Ramirez Vinolo ${ }^{\mathrm{c}}$, Gérard Lambeau ${ }^{\mathrm{d}}$ and Catarina Teixeira ${ }^{\mathrm{e}}$

${ }^{a}$ Departamento de Farmacologia, Universidade Federal de São Paulo, São Paulo/SP, Brazil ${ }^{\mathrm{b}}$ Instituto Clodomiro Picado, Facultad de Microbiología, Universidad de Costa Rica, San José, Costa Rica;

${ }^{c}$ Departamento de Genética, Evolução e Bioagentes, Instituto de Biologia, Universidade de Campinas, Campinas/SP, Brazil;

Université Côte d'Azur, CNRS, IPMC, Valbonne Sophia Antipolis, France;

${ }^{\mathrm{e}}$ Laboratório de Farmacologia, Instituto Butantan, São Paulo/SP, Brazil;

*Correspondence: Dr V Moreira, Ph.D. Mailing address: Departamento de Farmacologia, Universidade Federal de São Paulo (UNIFESP), Rua 3 de maio 100, Ed. INFAR, 3rd floor, CEP 04044-020, São Paulo, Brazil. Tel: +55-11-55764848. Fax: +55-11-55764447. email: vmoreira@unifesp.br or vanessam.epm@gmail.com

\section{Abstract}


The inducible cyclooxygenase $(\mathrm{COX})-2$ and prostaglandin $(\mathrm{PG}) \mathrm{E}_{2}$ production are distinctly

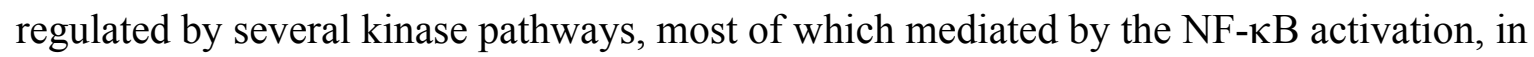
peritoneal macrophages stimulated by the snake venom secreted phospholipase $\mathrm{A}_{2}\left(\mathrm{sPLA}_{2}\right)$ myotoxin (MT)-III. However, the mechanism by which this group IIA sPLA 2 exerts its inflammatory effect on macrophages is not fully understood. Increasing evidence suggest that 12HETE, a product from arachidonic acid metabolism by 12-LO activation, is implicated in amplifying inflammation by regulating cell functions. In the present study the crosswise link between 12-HETE and MT-III-induced COX-2 and $\mathrm{PGE}_{2}$ release, associated to signaling pathways mediated by p38MAPK, PKC, ERK and NF-кB, were investigated. Results demonstrated that stimulation of isolated macrophages with MT-III cause activation of 12-LO in a time-dependent manner, with significant release of 12-HETE and without modification of 12-LO protein levels. The involvement of 12-HETE in MT-III-induced COX-2 expression and $\mathrm{PGE}_{2}$ production was demonstrated by using the selective 12-LO inhibitor baicalein. A significant decrease in the phosphorylation levels of MT-III-induced ERK1/2, but not of p38MAPK nor PKC, was observed in macrophages pre-incubated with the 12-LO inhibitor. In turn, MT-III-induced COX-2 protein expression and $\mathrm{PGE}_{2}$ release, but not NF- $\mathrm{BB}$ activation, were attenuated by pre-treating cells with PD98059, indicating the involvement of distinct pathways mediated by ERK in isolated macrophages. These results suggest that, in macrophages, MT-III-induced COX-2 protein expression and $\mathrm{PGE}_{2}$ release are distinctly and sequentially mediated through 12-HETE followed by ERK pathway activation, but are independent on NF-кB activation. Taken together, our findings highlight an unprecedented mechanism by which 12-HETE regulates one of the distinct signaling pathways for MT-III-induced COX-2 expression and $\mathrm{PGE}_{2}$ release in macrophages. These results provide new knowledge on the proinflammatory mechanisms of action of group IIA sPLA $\mathrm{A}_{2}$ from snake venom. 
Keywords: snake venom group IIA sPLA 2 , prostaglandin $\mathrm{E}_{2}$, 12-hydroxyeicosatetraenoic acid, cyclooxygenase-2, 12-lipoxygenase, inflammation, macrophages

\begin{abstract}
Abbreviations: 12-LO: 12-lipoxygenase; 12-HETE: 12-hydroxyeicosatetraenoic acid; PLA, phospholipase $\mathrm{A}_{2}$; PG, prostaglandin; COX, cyclooxygenase; MT-III, myotoxin-III; AA: arachidonic acid; MAPK, mitogen-activated protein kinases; PI3K, phosphatidylinositol 3-kinase; PKC, protein kinase C; PTK, protein tyrosine kinase; ERK 1/2, extracellular-signal-regulated kinases, NF-кB, nuclear factor-kappa B
\end{abstract}

\title{
1.Introduction
}

Secreted phospholipases $\mathrm{A}_{2}\left(\mathrm{sPLA}_{2}\right)$ are a group of enzymes with several biological functions, including transduction of signals encompassing the synthesis of lipid compounds and membrane repair, up to the generation of second messengers [Valentin, 2000; Brown et al., 2003]. These enzymes are abundant in nature and have been classified into 10 distinct groups, on the basis of their source, amino acid sequences and biochemical characteristics (IB, IIA, IIC, IID, IIE, IIF, III, V, X, XIIA and XIIB) [Murakami et al., 2010 and 2015]. The sPLA ${ }_{2}$ s hydrolyze the membrane phospholipids at the $s n-2$ position generating free fatty acids such as arachidonic acid (AA). AA is a substrate for various enzymatic pathways, mediated by cyclooxygenases (COX) and lipoxygenases (LO), whose activities lead to the production of diverse inflammatory lipid mediators, such as prostaglandins (PG), leukotrienes (LT), hydroxyeicosatetraenoic (HETE), among others [W.S. Powell, J. Rokach, 2015; D. Sacerdoti et al., 2015]. These, in turn, are capable of regulating a variety of cell functions [Powell and Rokach, 2015; K. Kawahara et al., 2015, K]. Among the secreted $\mathrm{PLA}_{2} \mathrm{~S}$, group IIA PLA $2 \mathrm{~S}$ have been considered clinically relevant due to their involvement in several inflammatory human diseases and envenomation by viperid snake venoms [J.S. Rana et 
al., 2009; P. Gałecki et al., 2012; M. Menschikowski et al., 2013; M. Chacur et al., 2004; Teixeira et al., 2003; Chaves et al., 1998].

Previous studies have shown that lipid mediators derived from AA are involved in the local inflammatory response induced by a group IIA snake venom sPLA2, named myotoxin-III (MT-III), isolated from Bothrops asper venom [Chaves et al., 1998; Chacur et al., 2003; Moreira et al., 2008]. Studies in in vivo experimental models have shown that MT-III promotes acute inflammatory response such as edema, pain and leukocyte accumulation at the site of injection by enhancing the production of inflammatory mediators including eicosanoids (Chaves et al., 1998; Chacur et al., 2003; Zuliani et al., 2005; Moreita et al., 2008]. Among these latters, $\mathrm{PGE}_{2}$ is a major lipid mediator involved in MT-III-induced proinflammatory events (Moreira et al., 2008; 2014), and its involvement in vasodilation, nociception and increased vascular permeability has been well established (Hata et al., 2004; K. Kawahara et al., 2015, K. Omori et al., 2014]. Investigation using isolated macrophages and neutrophils have previously demonstrated that stimulation with MT-III resulted in COX-2-dependent release of $\mathrm{PGE}_{2}$ (Moreira et al., 2008; 2011). In macrophages, these effects were characterized by a prominent release of AA and activation of distinct protein kinases, including those of the MAPK family (p38MAPK or ERK), PI3K and PKC, as well as, nuclear factor kappa B (NF-кB) [Moreira et al., 2008; 2014]. However, the signal transduction pathways leading to $\mathrm{SPLA}_{2}$ MT-III-promoted protein expression of COX-2 and production of AA and $\mathrm{PGE}_{2}$ levels in macrophages are still poorly understood. It is known that membrane cleavage products generated by $\mathrm{SPLA}_{2} \mathrm{~s}$ are important bioactive mediators involved in the induction and release of COX-2 and $\mathrm{PGE}_{2}$, respectively, by activating intracellular signaling mechanisms in various cells (Ruipérez et al., 2007; Kim et al., 2008; Hughes-Fulford et al., 2001; Oh detal., 2000 ).

Some studies have shown that 12-HETE, the main product generated from the AA metabolism by $12-\mathrm{LO}$, is associated with amplification of inflammatory processes [C.C. Hedrick et al., 1999; J. Shin et al., 2002, Powell and Rokach, 2015, Duchez et al., 2015; D.A. Taylor-Fishwick 
et al., 2015]. 12-LO and 12-HETE play important regulatory role on iNOS expression and NO production in interleukin-1 $\beta$-stimulated vascular smooth muscle cells [T. Hashimoto et al., 2003]. There are increasing lines of evidence demonstrating that 12-HETE regulates expression of COX-2 and generation of its major product $\mathrm{PGE}_{2}$ [X. Han et al., 2002; Woo et al., 2006, Xu et al., 2006, Niknami et al., 2010). Moreover, the regulatory effects exerted by this12-LO metabolite involve activation of protein kinases, such as p38MAPK, ERK and PI3K [S. Agarwal et al., 2009, X.Z. Ding et al., 2001, R.A. Stockton, B.S. Jacobson, 2001, Y. Wen Y et al., 2008]. However, there is no information about the roles played by 12-LO and 12-HETE in SPLA $_{2}$ MT-III-induced COX-2 expression and release of $\mathrm{PGE}_{2}$. Taking into account the above information and the fact that AA released by the action of $\mathrm{PLA}_{2} \mathrm{~S}$ is metabolized by diverse enzymatic pathways, including COX and LOXs, we investigated the involvement of 12-LO and 12-HETE in SPLA 2 MT-III-induced COX-2

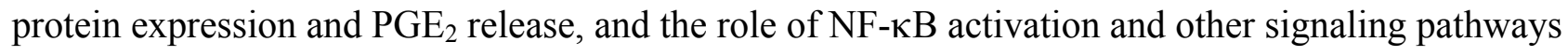
such as p38 MAPK, PKC or ERK.

\section{Material and Methods}

\subsection{Reagents}

12-HETE and $\mathrm{PGE}_{2}$ enzyme immunoassay kits, rabbit polyclonal anti-murine 12-LO and COX-2, and baicalein compound were purchased from Cayman Chemicals (Ann Arbor, MI, USA); mouse monoclonal anti- $\beta$-actin was from Sigma Aldrich Co. (St. Louis, MO, USA); peroxidaseconjugated secondary sheep anti-mouse or donkey anti-rabbit antibodies were from GE Healthcare (Buckinghamshire, UK). PD98059 was purchased from Calbiochem-Novabiochem (La Jolla, CA, USA). Antibodies phospho-ERK (p-p44/42 MAPK) and ERK (p44/42 MAPK) were from Cell Signalling Technology (Danvers, MA). RPMI 1640 was purchased from Sigma-Aldrich. Ethanol

grade was obtained from Merck (Darmstadt, Germany). The salts used were purchased from Merck, GE Healthcare (Buckinghamshire, UK) and Bio-Rad (Hercules, CA). 


\subsection{Animals}

Male Swiss mice (18-20 g) were used. These animals were housed in temperature-controlled rooms, with a relative humidity of $65.3 \pm 0.9 \%$ and $12 \mathrm{~h}$ dark-light period, and received water and food ad libitum. The animals and research protocols used in this study followed the guidelines of the Ethical Committee for use of animals of Instituto Butantan, SP, Brazil (CEUAIB, protocol number 1323/14) and international policies of experimental animal care. All efforts were made to minimize the number of animals used and their suffering.

\subsection{Phospholipase $A_{2}$ MT-III}

MT-III was isolated by ion-exchange chromatography on CM-Sephadex C-25 from Bothrops asper venom (Gutiérrez \& Lomonte, 1989). A final purification step by high-performance liquid chromatography (HPLC) on a C8 column was introduced. Homogeneity was demonstrated by analytical reverse phase HPLC. The absence of endotoxin contamination in the MT-III preparation was demonstrated by the quantitative Limulus amebocyte lysate (LAL) test (Takayama et al., 1994), which revealed undetectable levels of endotoxin $(<0.125 \mathrm{EU} / \mathrm{mL})$.

\subsection{Resident peritoneal macrophages collection and culture}

Resident peritoneal macrophages were harvested by washing peritoneal cavities of mice with $2 \mathrm{~mL}$ of apyrogenic saline solution. Aliquots of the washes were used to count total cell numbers in a Neubauer's chamber after dilution $(1: 20, \mathrm{v} / \mathrm{v})$ in Turk solution. Aliquots of either $1 \times 10^{6}$ or $5 \times 10^{6}$ cells/mL were preincubated in 24- and 6-well polystyrene culture plates, respectively, for $3 \mathrm{~h}$, with RPMI 1640 medium supplemented with $1 \%$ of L-glutamine and $100 \mu \mathrm{g} / \mathrm{mL}$ of gentamicine, at $37^{\circ} \mathrm{C}$ and $5 \% \mathrm{CO}_{2}$ atmosphere. Non-adherent cells were removed by three washes with RPMI medium. After cell adhesion, peritoneal cells, which were initially composed of $40-50 \%$ of F4/80 positive cells and more than $30 \%$ of CD19 positive cells, became enriched in F4/80 positive cells (more than 
$90 \%$ of the cells), as demonstrated by performing flow cytometry using the F4/80-fluorescein isothiocyanate (Clone A3-1, Serotec) and CD19-phycoerythrin antibodies (Clone 1D3, BD Bioscience) and a FACSCalibur flow cytometer (Becton \& Dickinson, San Jose, CA, USA). MT-III $(0.4 \mu \mathrm{M})$ was added and, after $4.5 \mathrm{~h}$, the cell suspension was harvested and centrifuged at $500 \mathrm{~g}$ for 6 min at $22^{\circ} \mathrm{C}$. The supernatants were stored at $-80^{\circ} \mathrm{C}$ and later used for determination of 12-HETE or $\mathrm{PGE}_{2}$ by EIA kit, whereas the cell pellets were used to determine the protein expression of COX2, 12-LO, p-ERK and ERK by western blotting or nuclear translocation of NF-אB by electrophoretic mobility shift assay (EMSA). Where appropriate, the following inhibitors were used: $40 \mu \mathrm{M}$ of baicalein (Peng et al., 2008; Qi et al., 2013) an inhibitor of 12-LO and $50 \mu \mathrm{M}$ of PD98059 (S. Nishimoto, E. Nishida, 2006), selective inhibitor of ERK phosphorylation. Cells treated with either inhibitors or MT-III or both were analyzed for viability by measuring lactate dehydrogenase (LDH) release and by the tetrazolium-based (MTT) colorimetric assay. No significant changes in cell viability were observed with the above agents or vehicle at their respective concentrations (data not shown).

\subsection{Quantification of $P G E_{2}$ and 12-HETE concentration}

Concentrations of $\mathrm{PGE}_{2}$ and 12-HETE were determined by enzyme immunoassays, using commercial kits. In brief, $50 \mu \mathrm{L}$ aliquots of cell supernatant were incubated with the eicosanoids conjugated with acetylcholinesterase and the specific rabbit antiserum in 96-well plates coated with anti-rabbit IgG mouse monoclonal antibody. After addition of the substrate, the absorbance of the samples was recorded at $405 \mathrm{~nm}$ in a microplate reader (Labsystem Multiscan), and concentrations of $\mathrm{PGE}_{2}$ or 12-HETE were estimated from standard curves.

\subsection{Western blotting}


COX-2 and 12-LO protein expression were detected in peritoneal leukocytes or macrophages by western blotting. Aliquots of $1 \times 10^{6}$ cells were lysed with $100 \mu \mathrm{L}$ of sample buffer (0.5 M Tris-HCl, pH 6.8, 20\% SDS, 1\% glycerol, $1 \mathrm{M} \beta$-mercaptoethanol, $0.1 \%$ bromophenol blue) and boiled for $10 \mathrm{~min}$. The samples were subjected to SDS-polyacrylamide gel electrophoresis (SDS-PAGE) on 10\% bis-acrylamide gels overlaid with a 5\% stacking gel. Proteins were then transferred to nitrocellulose membrane (GE Healthcare, Buckinghamshire, UK) using a Mini TransBlot $^{\circledR}$ (Bio Rad Laboratories, Richmond, CA, USA). The membrane was blocked for $1 \mathrm{~h}$ with 5\% w/v nonfat dry milk in Tris-buffered saline-Tween 20 (TTBS) (20 mM Tris, $100 \mathrm{mM} \mathrm{NaCl}$ and $0.5 \%$ Tween 20$)$, and incubated with primary antibodies against COX-2 (1:1,500) or 12-LO $(1: 5,000)$ and $\beta$-actin $(1: 2,000)$. To analyze the presence of p-ERK induced by MT-III, the membrane was blocked for $1 \mathrm{~h}$ in TTBS/5\% w/v BSA and incubated with antibodies against $\mathrm{p}$ p44/42 MAPK or p44/42 MAPK at $4{ }^{\circ} \mathrm{C}$ with gentle shaking, overnight. The membrane was then washed and incubated with appropriate secondary antibody conjugated to horseradish peroxidase. Detection was performed using the enhanced chemiluminescence method (GE Healthcare, Buckinghamshire, UK). Densities of the band were determined by a LAS Imager 3000 (GE Healthcare, Buckinghamshire, UK) using the image analysis software from Quantity One ${ }^{\circledR}$ (GE Healthcare, Buckinghamshire, UK).

\subsection{Electrophoretic Mobility Shift Assay (EMSA)}

NF-кB binding capacity was assessed by EMSA. Nuclear extracts from peritoneal adherent macrophages $\left(3 \times 10^{6}\right.$ cells/well) were obtained as previously described (Rong \& Baudry, 1996), and protein concentration was determined by the Bradford method (Bradford et al., 1976). NF-кB binding capacity was evaluated as previously described (Vinolo et al., 2011). Briefly, end-labeled $\left[\gamma_{-}{ }^{32} \mathrm{P}\right]$ ATP oligonucleotides containing an NF- $\mathrm{KB}$ consensus-binding site (5' -

AGTTGAGGGGACTTTCCCAGGC-3') were incubated for $20 \mathrm{~min}$ at room temperature with $5 \mu \mathrm{g}$ 
of nuclear extract protein. DNA-protein complexes were then separated on a $5.5 \%$ non-denaturing polyacrylamide gel using a running buffer of $45 \mathrm{mM}$ Tris, $45 \mathrm{mM}$ borate and $1 \mathrm{mM}$ EDTA buffer. The gels were vacuum dried $\left(80^{\circ} \mathrm{C}\right)$ and subjected to autoradiography. The blots were analyzed by scanner densitometry (STORM 840, Dynamic Molecular, Sunnyvale, CA, USA), and the results were obtained through densitometric analysis. The results are expressed relative to the control condition (unstimulated control).

\subsection{Statistical analysis}

Results are expressed as mean \pm SEM. Differences among groups were analyzed by oneway analysis of variance (ANOVA) followed by Tukey's range test. Values of probability lower than $5 \%(p<0.05)$ were considered as significant.

\section{Results}

3.1. MT-III promotes 12-HETE production but does not induce expression of the 12-LOX protein Considering that 12-LO is the key enzyme in the 12-HETE biosynthetic pathway, the effect of sPLA2 MT-III on this enzyme was assessed in isolated peritoneal macrophages. The concentration of sPLA 2 MT-III $(0.4 \mu \mathrm{M})$ used along this study was based from previous data showing the ability of MT-III to stimulate murine macrophages at this concentration (Moreira et al., 2008; 2011; 2014). As demonstrated in Fig 1A, incubation of isolated macrophages with MT-III significantly increased 12-HETE concentration in a time-dependent manner, with levels ranging from 21461 \pm 11012 at 30 $\min$ to $78093 \pm 10333 \mathrm{pg} / \mathrm{mL}$ at $3 \mathrm{~h}$ when compared to respective control cells $(\mathrm{p}<0.05)$, incubated with saline solution, which ranged from $2200 \pm 541.5$ to $7170 \pm 4176 \mathrm{pg} / \mathrm{mL}$ (Fig. 1A). Maximal release occurred at $30 \mathrm{~min}$ with an $87 \%$ increase over levels of control cells. Because 12-LO is a key enzyme in the 12-HETE biosynthetic pathway, the effect of sPLA 2 MT-III on the expression of 
this protein was assessed in isolated macrophages by western blot. As shown in Figs 1B and C, the expression of $12-\mathrm{LO}$ did not differ $(\mathrm{p}<0.05)$ between macrophages incubated with MT-III versus those incubated with only saline.

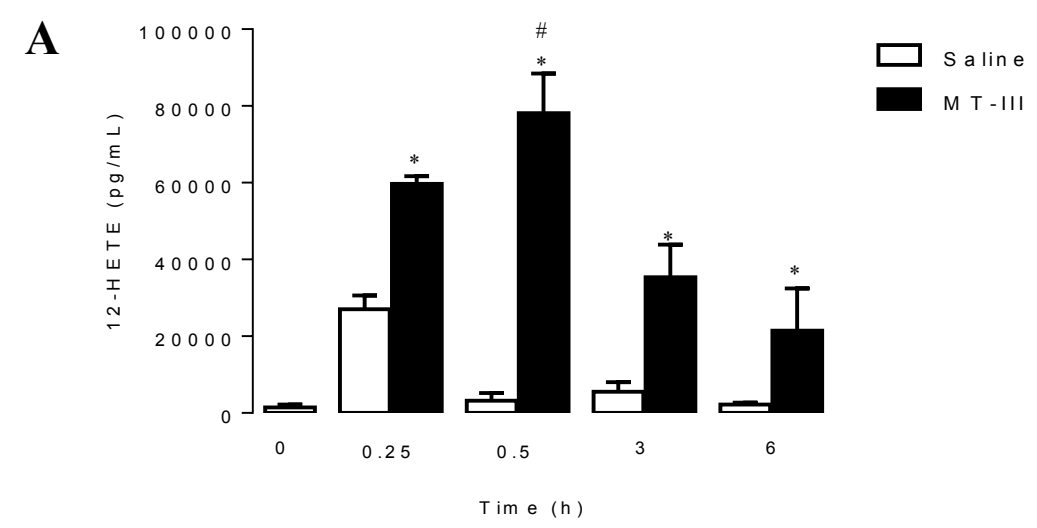

$\mathbf{R}$

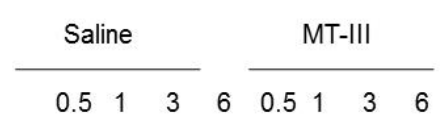

(h)

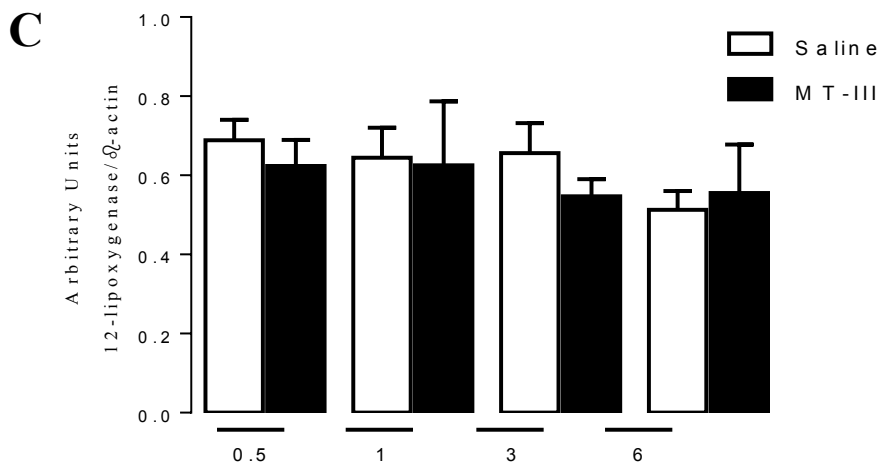

Tim e (h)

Figure 1. Effect of MT-III on the release of 12-HETE and protein expression of 12-LO by macrophages. Cells $\left(1 \times 10^{6}\right)$ were incubated with MT-III $(0.4 \mu \mathrm{M})$ or saline solution (Control) for 15 min or $0.5,1,3$ or 6 h. 12-HETE was quantified in culture supernatants by specific EIA (A); Western blotting of 12-LO and $\beta$-actin (loading control) (B); bar graph shows densitometric analysis of immunoreactive 12-LO in AU, normalized with $\beta$-actin (C). Results are expressed as mean \pm SEM from 3 to 4 experiments. ${ }^{*} p<0.05$ as compared to the corresponding macrophages 
incubated with saline solution. ${ }^{*} p<0.05$ as compared to macrophages incubated with MT-III at 15 $\min$ or 1,3 or $6 \mathrm{~h}$.

\subsection{Baicalein inhibits COX-2 expression, as well as $P G E_{2}$ and 12-HETE production induced by}

\section{MT-III in macrophages}

We next examined the involvement of the 12-LO pathway on expression of COX-2 protein and $\mathrm{PGE}_{2}$ release induced by sPLA 2 MT-III. Pretreatment of macrophages with baicalein $(40 \mu \mathrm{M})$, an inhibitor of 12-LO, significantly reduced COX-2 protein expression by $47 \%$ and abrogated $\mathrm{PGE}_{2}$ production induced by MT-III in isolated macrophages (Fig. 2A, B and C). In addition, as shown in Fig 2D, pretreatment of macrophages with baicalein also abrogated MT-III-induced release of 12HETE, the main product from the 12-LO pathway, implicating 12-HETE as an important mediator regulating both COX-2 protein expression and $\mathrm{PGE}_{2}$ production induced by $\mathrm{SPLA} 2 \mathrm{MT}-\mathrm{III}$ in isolated macrophages.

A

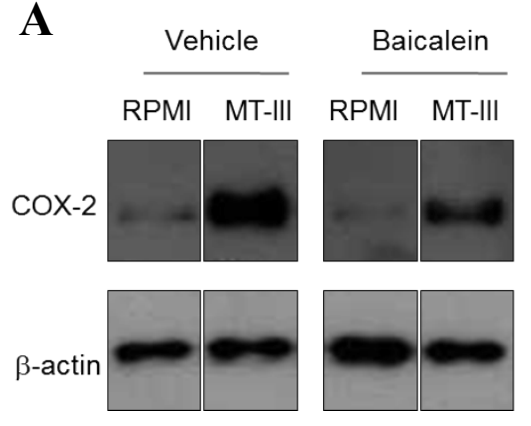

B

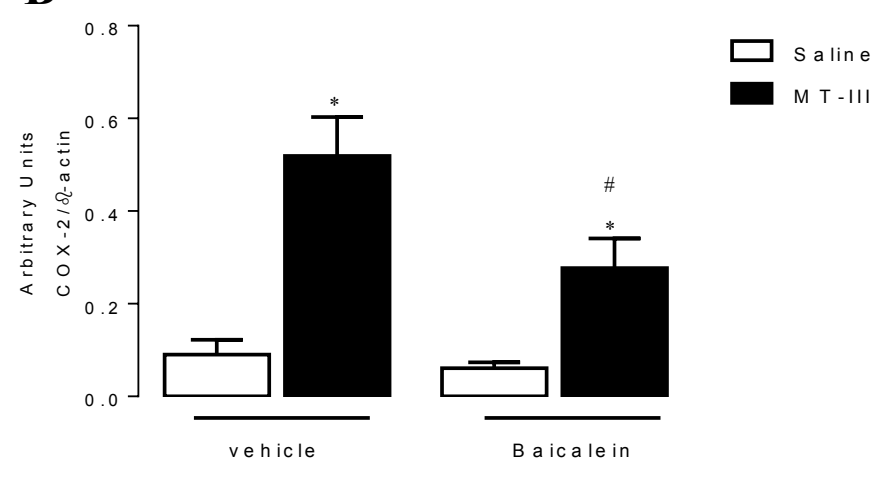

C

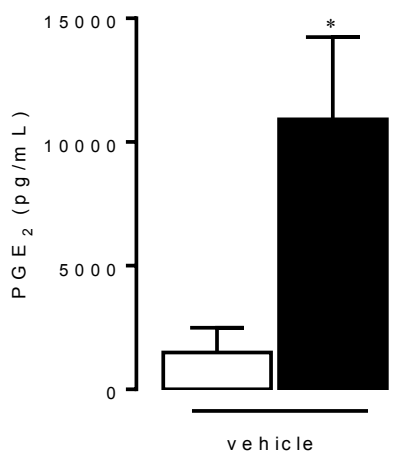

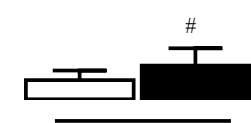

$B$ a ic a le in
D

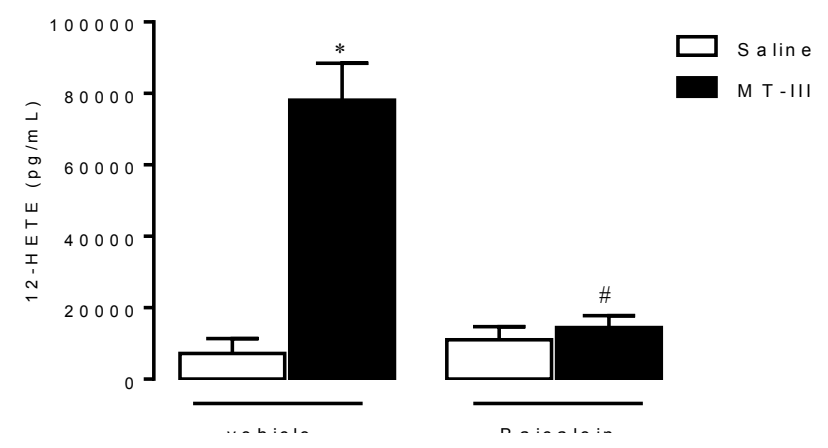


Figure 2. Effect of baicalein on COX-2 expression, $P G E_{2}$ and 12-HETE production induced by MTIII in isolated macrophages. Resident peritoneal macrophages ( $1 \times 10^{6}$ cells) were pretreated for 30 min with baicalein $(40 \mu \mathrm{M})$ and then incubated during $3 \mathrm{~h}$ with MT-III $(0.4 \mu \mathrm{M})$. Western blotting of COX-2 and $\beta$-actin (loading control) of cells treated with MT-III (A); bar graph shows densitometric analysis of immunoreactive COX-2 in $\mathrm{AU}$, normalized with $\beta$-actin (B); $\mathrm{PGE}_{2}$ and 12-HETE were quantified in culture supernatants by specific EIA (C, D). Results are expressed as mean \pm SEM from 3 to 4 experiments. ${ }^{*} p<0.05$ as compared with macrophages incubated with saline solution. ${ }^{\#} p<0.05$ as compared with macrophages incubated with MT-III and vehicle.

\subsection{Baicalein inhibits ERK phosphorylation induced by MT-III in peritoneal macrophages}

It has been previously reported that protein kinases are activated by $12-\mathrm{LO}$ metabolites in various cell types (S. Agarwal et al., 2009, X.Z. Ding et al., 2001, R.A. Stockton, B.S. Jacobson, 2001, Y. Wen Y et al., 2008). To evaluate the role of the 12-LO pathway in the actions of MT-III on kinase activation, we tested the effects of baicalein on MT-III-stimulated p38 MAPK, PKC and ERK phosphorylation. MT-III-induced ERK (Fig 3D and 3C) but not PKC or p38MAPK protein phosphorylation was inhibited by baicalein when compared with macrophages treated either with MT-III alone or pretreated with vehicle. Treatment of macrophages in culture with sPLA $_{2}$ MT-III $(0.4 \mu \mathrm{M})$ increased ERK phosphorylation as early as $5 \mathrm{~min}$, with a peak at $15 \mathrm{~min}$, which was followed by a rapid decrease over time (Fig 4 A and B). This finding indicates that the principal product of 12-LOX catalytic activity, 12-HETE, is involved in ERK phosphorylation induced by MT-III in isolated macrophages. 

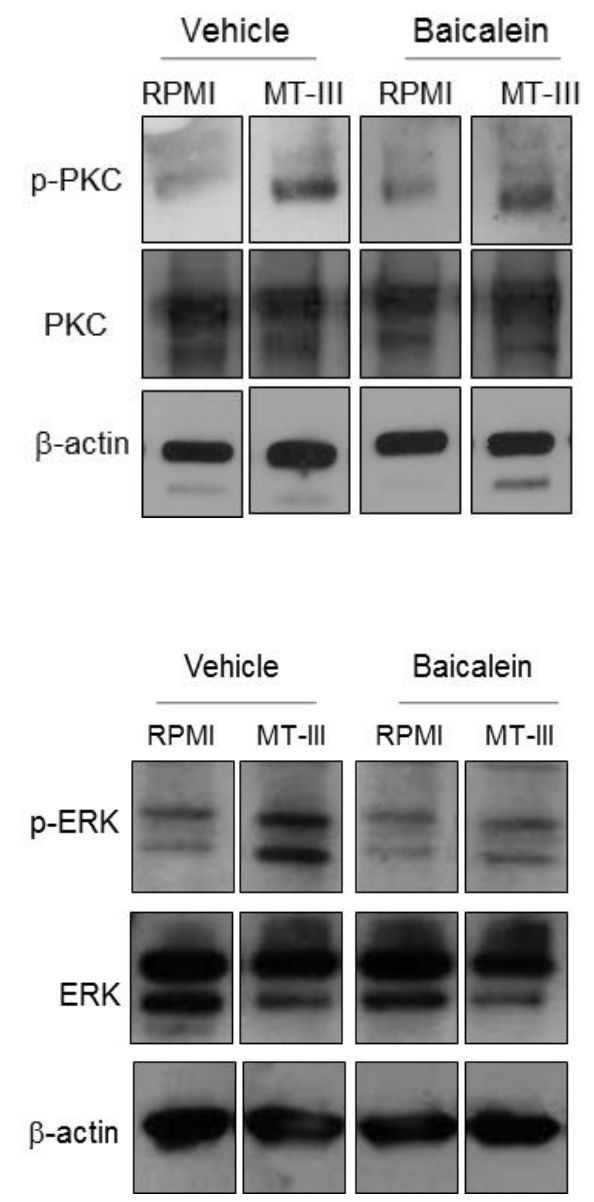

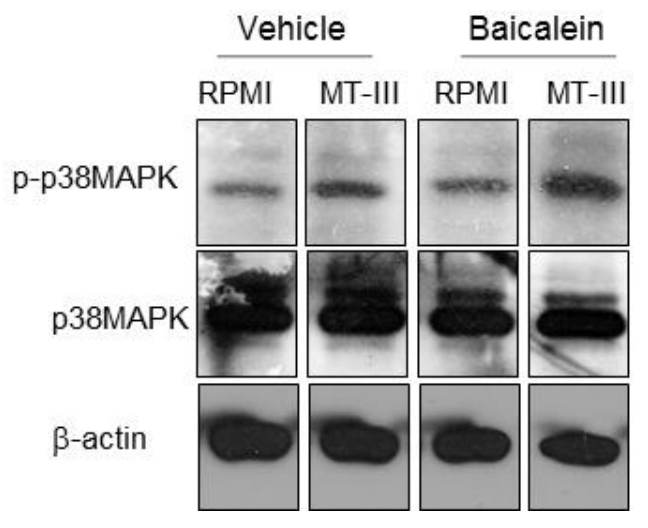

D

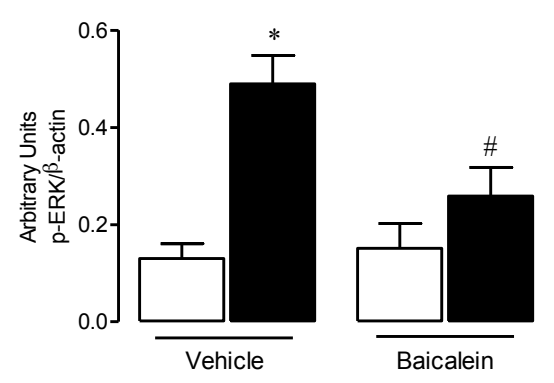

$\mathbf{E}$

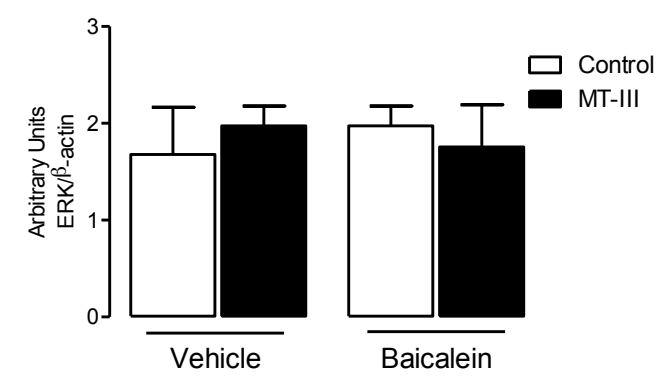

Figure 3. Effect of baicalein on $p-P K C, p-p 38 M A P K$ and $p$-ERK protein expression induced by $M T$-III in macrophages. Resident peritoneal macrophages ( $1 \times 10^{6}$ cells) were pretreated for $30 \mathrm{~min}$ with baicalein $(40 \mu \mathrm{M})$ or vehicle (control), and then incubated during 30 min with MT-III $(0.4 \mu \mathrm{M})$ and. western blotting of p-PKC and PKC (A); p-p38MAPK and p38MAPK (B); p-ERK and ERK (C) and $\beta$-actin (loading control) of cells treated with MT-III; bar graph shows densitometric analysis of immunoreactive bands of p-ERK and ERK in AU, both normalized with $\beta$-actin (D and E). Results are expressed as mean \pm SEM from 3 experiments. ${ }^{*} p<0.05$ as compared with macrophages incubated with saline solution. ${ }^{\#} p<0.05$ as compared with macrophages incubated with MT-III and vehicle. 


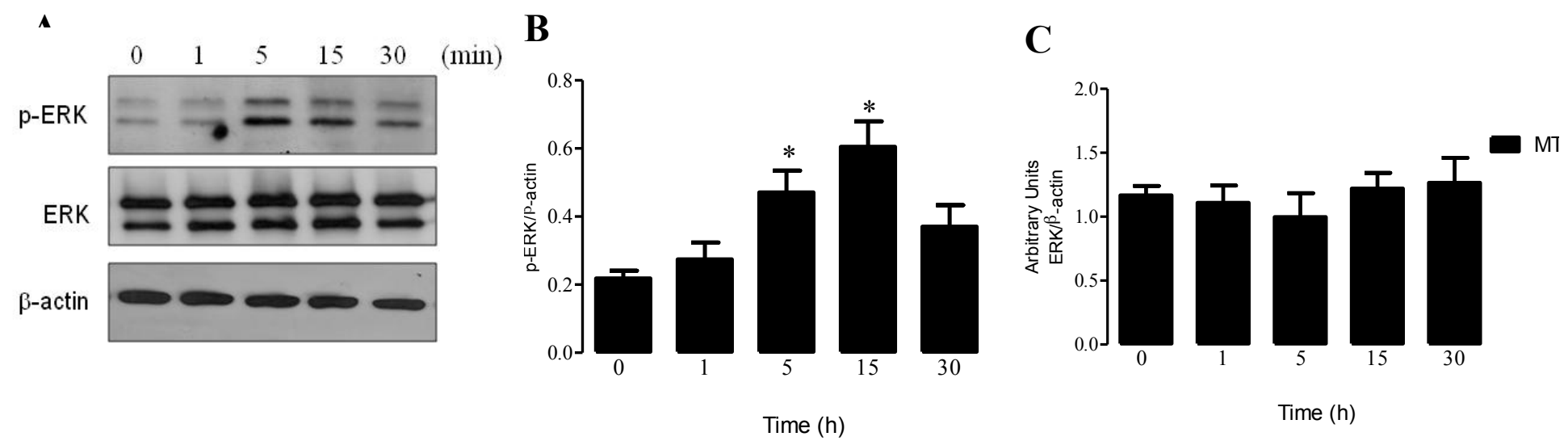

Figure 4. ERK phosphorylation induced by MT-III in isolated macrophages. Resident peritoneal macrophages $\left(1 \times 10^{6}\right.$ cells) were incubated during $1,5,15$ and 30 min with MT-III $(0.4 \mu \mathrm{M})$. Western blotting of p-ERK and ERK and $\beta$-actin (loading control) (A); Densitometric analysis of immunoreactive bands of p-ERK and ERK in AU, both normalized with $\beta$-actin (D and E). Results are expressed as mean \pm SEM from 3 experiments. ${ }^{*} p<0.05$ as compared with macrophages incubated with time zero.

3.4 PD98059 inhibits COX-2 expression and $P G E_{2}$ production, but not $N F-\kappa B$ activation induced by MT-III in macrophages

We have shown that protein kinases participate to the signaling triggered by snake venom sPLA $\mathrm{A}_{2} \mathrm{~S}$ group IIA in isolated macrophages (Moreira et al., 2013, 2014). To assess the role of ERK kinases in MT-III-induced $\mathrm{PGE}_{2}$, we investigated the effects of the specific inhibitors of ERK phosphorylation (PD98059) on MT-III-induced COX-2 expression and $\mathrm{PGE}_{2}$ release. Fig. 5 A, B and $\mathrm{C}$ depict MT-III-induced COX-2 protein expression and $\mathrm{PGE}_{2}$ levels in macrophages pretreated with PD98059 or with vehicle. Unstimulated macrophages showed a weak basal COX-2 protein 
expression and $\mathrm{PGE}_{2}$ release when pretreated with or without inhibitors of kinases (Fig.5A and B). Previous findings have shown that stimulation of resident macrophages with MT-III resulted in increased expression of COX-2 and $\mathrm{PGE}_{2}$ production, which was dependent on NF- $\mathrm{KB}$ activation (Moreira et al., 2014). Therefore, to determine whether activation of NF- $\kappa \mathrm{B}$ is mediated by ERK signaling pathway, we used the same specific inhibitor PD98059 and evaluated the translocation of NF- $\kappa B$ to the macrophage nucleus. Fig 5D shows that pretreatment of resident macrophages with PD 98059 did not alter MT-III-induced activation of NF-אB. Taken together, these results suggest that MT-III- stimulates COX-2 expression and $\mathrm{PGE}_{2}$ release through a process independent of NF$\kappa \mathrm{B}$ and ERK signaling pathways.
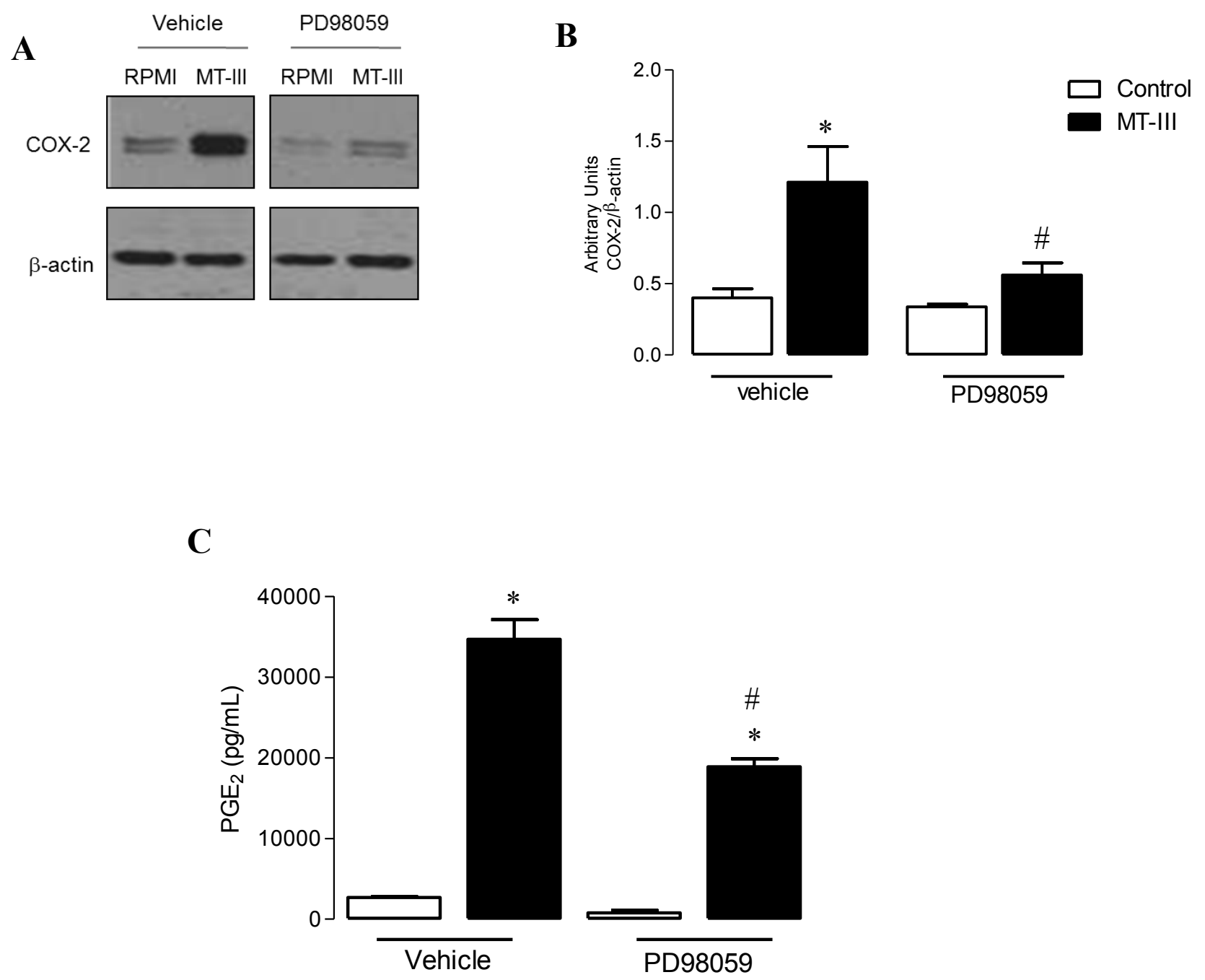


\section{D}
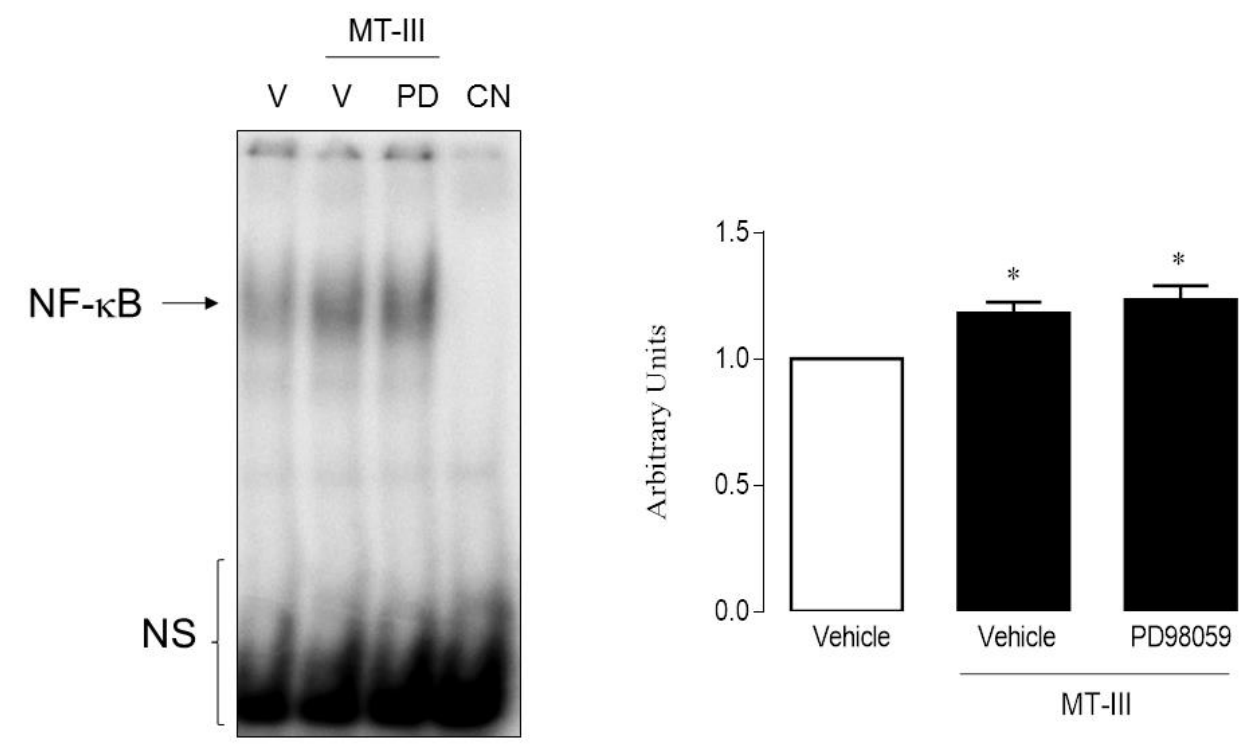

Figure 5. Effect of $P D 98059$ on COX-2 protein expression, $P G E_{2}$ release and $N F-\kappa B$ activation induced by MT-III in isolated macrophages. MT-III activates NF-KB in macrophages in culture. $(\mathrm{A}, \mathrm{C})$ Nuclear extracts were prepared and assayed for $\mathrm{\kappa B}$ probe activity with ${ }^{32} \mathrm{P}$-labeled doublestranded oligonucleotide $\kappa B$ using EMSA. (B,D) Densitometric analysis of NF- $\kappa B$ band intensities. Results are expressed as mean \pm SEM from 3 experiments. ${ }^{*} p<0.05$ as compared with control value. $\mathrm{NS}=$ Non specific band; $\mathrm{V}=$ Vehicle; $\mathrm{NC}=$ Negative control.

\section{Discussion}

Since the production of lipid mediators is highly regulated by a variety of extracellular stimuli, it is relevant to study the mechanisms involved in the ability of group IIA sPLA $\mathrm{S}_{2}$ from snake venom targets to produce $\mathrm{PGE}_{2}$ and regulate $\mathrm{COX}-2$ expression.

We show here that peritoneal macrophages produce an early and sustained release of 12- (S)hydroxy-eicosatetraenoic (12-HETE) when stimulated with the snake venom sPLA 2 MT-III. 
Previous work demonstrated that bee venom (Apis mellifera) and snake venom (Bungarus multicinctus) $\mathrm{sPLA}_{2} \mathrm{~S}$ also stimulate production of 12-(S)-hydroxy(peroxy)eicosatetraenoic (12H(P)ETE) by platelets (Coffey et al., 2004), indicating that various venom sPLA ${ }_{2}$ s can activate 12LO. Furthermore, studies have shown an association between mammalian $\mathrm{PLA}_{2} \mathrm{~s}$ and 12-LO during the inflammatory response (Balboa et al., 2003; Coffey et al., 2004; Duchez et al., 2015). More specifically, PLA 2 s from groups IV and IIA have been shown to provide arachidonic acid to 12-LO, causing an increase of 12-HETE levels, thereby contributing to inflammatory injury (Coffey et al., 2004; Duchez et al., 2015). To the best of our knowledge, this is the first demonstration that a snake venom group IIA $\mathrm{sPA}_{2}$ is capable of increasing the activity of 12-LO in macrophages. Three isoforms of 12-LO have been described in mice: platelet-type 12-LO; macrophage or leukocytetype 12-LO and epidermal-type 12-LO (Yoshimoto, Y. Takahashi 2002). 12-HETE, which is the main product generated by leukocyte-type 12-LO, has been shown to induce inflammatory events, such as vasodilation, increased adhesion molecule expression, induction of monocyte migration, and release of inflammatory mediators, such as CCL2, IL-6, TNF- $\alpha$ (Patricia et al., 1999, Reilly et al., 2004; Faulkner et al., 2015, Giunti et al., 2008; Wen et al., 2007 and 2008). Previous work of our group has shown that MT-III displays inflammatory activity at the site of injection (Zuliani et al., 2005; Moreira et al., 2008), inducing a prominent release of $\mathrm{PGE}_{2}$ from macrophages by upregulating COX-2 expression, which is dependent on activation of distinct protein kinases (Moreira et al. 2014). The involvement of 12-LOX as the mechanism underlying MT-III- induced upregulation of COX-2 expression was further confirmed by inhibiting COX-2 protein expression by baicalein ( Tong et al., 2002b,Yoshimura et al., 2004a; XU et al., 2012). Thus, MT-III activates downstream pathways required for up-regulation of $\mathrm{COX}-2$ expression and $\mathrm{PGE}_{2}$ production through activation of 12-LO and release of 12-HETE. Our data are in agreement with findings that 12-HETE or 12-LO activity are involved in COX-2 and $\mathrm{PGE}_{2}$ induction in pancreatic or mesangial cells (Di Mari et al., 2007, Han et al., 2002; Xu et al., 2006). To our knowledge, this is the first 
demonstration of a link between 12-HETE and group IIA sPLA 2 -induced expression of COX-2 and production of $\mathrm{PGE}_{2}$.

12-HETE stimulates signaling pathways involving protein kinases that play regulatory roles on the route of cyclooxygenase and production of lipid mediators (Chakrabarti et al., 2009; Szekeres et al., 2000; Chen et al., 2008; Xu et al., 2006, Han et al., 2002). It has been shown that 12-HETE can activate p38 mitogen-activated protein kinases (p38MAPK), protein kinase C (PKC) and extracellular-signal-regulated kinases (ERK) to up-regulate inflammatory effects in various types of cells (Di Mari et al., 2007; Wen et al., 2008 and 2007; Garcia-Verdugo et al., 2012). We thus investigated the mechanisms by which 12-HETE regulates MT-III-induced COX-2 protein expression and $\mathrm{PGE}_{2}$ release. Results show that inhibition of 12-HETE reduced ERK activation, but not p38MAPK nor PKC. Our previous work demonstrated that MT-III is able to activate phosphorylation of p38MAPK and PKC in isolated macrophages (Moreira et al., 2014). However, we have demonstrated that sPLA 2 MT-III-induced COX-2 protein expression and $\mathrm{PGE}_{2}$ release were regulated by $\mathrm{p} 38 \mathrm{MAPK}$ and PKC signaling proteins. The present findings evidenced that activation of both p38MAPK and PKC phosphorylation by MT-III is largely independent on 12-LO up-regulation in isolated macrophages. This finding highlights that the up-regulation of 12-LO by MT-III regulates ERK $1 / 2$ phosphorylation in isolated macrophages. This effect suggests that 12HETE is an upstream activator of 12-HETE-induced ERK 1/2 activation in these cells, upon stimulation by sPLA2 MT-III. The sequential activation of 12-HETE and ERK has been associated with mucus secretion in pulmonary inflammatory diseases (Garcia-Verdugo et al., 2012), pancreatic cancer cell proliferation (Ding et al., 2001) and other type of tumors (Szekeres et al., 2000; Agarwal et al., 2009).

Our results showed that MT-III induces the phosphorylation and activation of ERK, this effect being consistent with other studies in which activation of ERK is a key link in inflammation, cell proliferation and lipid body formation induced by type IIA $\mathrm{SPLA}_{2} \mathrm{~s}$ from both human [Martin et 
al., 2012; Yu et al., 2012; Hernandez et al., 2010; 1998] and Bothrops asper venom [Moreira et al., 2013; Giannotti et al., 2013; Leiguez et al.2011]. In addition, in this study, we showed that the activation of macrophages by MT-III leading to $\mathrm{PGE}_{2}$ production and COX-2 expression are largely dependent on ERK phosphorylation. This finding is in agreement with previous reports that ERK activation is involved in the biogenesis of eicosanoids induced by SPLA $_{2} \mathrm{~s}$ [Kikawada et al., 2007, Han et al., 2003] and other inflammatory mediators [Trigianni et al., 2009, Carmo et al., 2014]. In light of evidence that the ERK-activated $\mathrm{CPLA}_{2}$ is responsible for the selective release of arachidonic acid in $\mathrm{sPLA}_{2}$-stimulated mast cells [Kikawada et al., 2007; Han et al., 2003], or sPLA2 Lys-49-stimulated macrophage [Moreira et al., 2013; Giannotti et al., 2013] it is likely that activation of ERK is important for $\mathrm{CPLA}_{2}$-mediated $\mathrm{PGE}_{2}$ production induced by MT-III in isolated macrophages. In contrast, although we showed that blockade of MT-III function with ERK inhibitor is sufficient to suppress both $\mathrm{PGE}_{2}$ production and COX-2 expression, it was demonstrated that the same inhibitor did not suppress MT-III-induced NF- $\kappa$ B recruitment. It is hypothesized that there are other signaling pathways activated by MT-III involving other regulatory factors, because this sPLA $_{2}$ still induces the activation of NF- $\kappa B$ in the presence of ERK inhibitor. A similar effect was observed in relation to MT-III-induced PI3K phosphorylation, whose effect in $\mathrm{PGE}_{2}$ release and COX-2 protein expression in peritoneal macrophages was fully independent of NF-KB activation

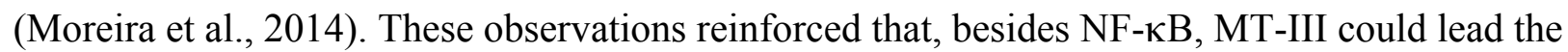
activation of other types of transcription factors. In agreement with this observation, there are reports that ERK 1/2 is linked with activator protein-1 (AP-1) activation [Hseu et al., 2012] or is associated to cAMP-response element-binding protein (CREB) phosphorylation (Eliopoulos et al., 2002, Ueno and Fujimor, 2011) for downstream COX-2 protein expression by different stimuli. Our results have not identified selected downstream pathways activated by ERK in the biosynthesis of COX-2 expression and $\mathrm{PGE}_{2}$ synthesis induced by MT-III. However, we observed that 12-LO and its product 12-HETE play an important role in upstream cascades involved in $\mathrm{SPLA}_{2}$-induced ERK 
phosphorylation. These findings imply a new aspect of the effect of group IIA sPLA 2 in macrophage inflammatory functions, in which distinct arachidonic acid metabolism products, produced by its catalytic activity, may positively regulate crosswise the $\mathrm{PLA}_{2}$-induced-COX-2 upregulation in pathophysiological conditions.

References:

E. Valentin, G. Lambeau, Increasing molecular diversity of secreted phospholipases A(2) and their receptors and binding proteins. Biochim. Biophys. Acta1488 (2000) 59-70.

W.J. Brown, K. Chambers, A. Doody, Phospholipase A2 (PLA2) enzymes in membrane trafficking: mediators of membrane shape and function. Traffic 4(200) 214-221.

M. Murakami, Y. Taketomi, C. Girard, K.Yamamoto, G. Lambeau, Emerging roles of secreted phospholipase A2 enzymes: Lessons from transgenic and knockout mice. Biochimie 92 (2010) 561-582.

M. Murakami, H. Sato, Y. Miki, K. Yamamoto, Y. Taketomi, A new era of secreted phospholipase $\mathrm{A}_{2}$, J. Lipid Res. 56 (2015) 1248-1261.

D. Sacerdoti, P. Pesce, M. Di Pascoli, S. Brocco, L. Cecchetto, M. Bolognesi, Arachidonic acid metabolites and endothelial dysfunction of portal hypertension. Prostaglandins Other Lipid Mediat. 120 (2015) 80-90.

W.S. Powell, J. Rokach, Biosynthesis, biological effects, and receptors of hydroxyeicosatetraenoic acids (HETEs) and oxoeicosatetraenoic acids (oxo-ETEs) derived from arachidonic acid. Biochim. Biophys Acta 1851(2015) 340-355.

J.S. Rana, M. Cote, J.P. Després, M.S. Sandhu, P.J. Talmud, E. Ninio, N.J. Wareham, J.J. Kastelein, A.H. Zwinderman, K.T. Khaw, S.M. Boekholdt, Inflammatory biomarkers and the prediction of coronary events among people at intermediate risk: the EPIC-Norfolk prospective population study. Heart 95(2009) 1682-1687. 
P. Gałecki, E. Gałecka, M. Maes, M. Chamielec, A. Orzechowska, K. Bobińska, A. Lewiński, J.J. Szemraj, The expression of genes encoding for COX-2, MPO, iNOS, and sPLA2-IIA in patients with recurrent depressive disorder, Affect. Disord. 138(2012) 360-366.

M. Menschikowski, A. Hagelgans, U. Schuler, S. Froeschke, A. Rosner, G. Siegert, Plasma levels of phospholipase A2-IIA in patients with different types of malignancies: prognosis and association with inflammatory and coagulation biomarkers, Pathol. Oncol. Res. 19 (2013) 839-846.

M. Chacur, I. Longo, G. Picolo, J.M. Gutiérrez, B. Lomonte, J.L. Guerra, C.F. Teixeira, Y. Cury, Hyperalgesia induced by Asp49 and Lys49 phospholipases A2 from Bothrops asper snake venom: pharmacological mediation and molecular determinants, Toxicon 41 (2003) 667-678.

M. Chacur, E.D. Milligan, E.M. Sloan, J. Wieseler-Frank, R.M. Barrientos, D. Martin, S. Poole, B. Lomonte, J.M. Gutiérrez, S.F. Maier, Y. Cury, L.R. Watkins, Snake venom phospholipase A2s (Asp49 and Lys49) induce mechanical allodynia upon peri-sciatic administration: involvement of spinal cord glia, proinflammatory cytokines and nitric oxide, Pain 108(2004) 180-191.

F. Chaves, G. León, V.H. Alvarado J.M. Gutiérrez, Pharmacological modulation of edema induced by Lys-49 and Asp-49 myotoxic phospholipases A2 isolated from the venom of the snake Bothrops asper (terciopelo), Toxicon 36(1998) 1861-1869.

C.F. Teixeira, E.C. Landucci, E. Antunes, M. Chacur, Y. Cury. Inflammatory effects of snake venom myotoxic phospholipases A2, Toxicon 42(2003) 947-962.

V. Moreira, J.M. Gutiérrez, A.M. Soares, S.R. Zamunér, E. Purgatto, C.F. Teixeira, Secretory phospholipases $\mathrm{A}(2)$ isolated from Bothrops asper and from Crotalus durissus terrificus snake venoms induce distinct mechanisms for biosynthesis of prostaglandins E2 and D2 and expression of cyclooxygenases, Toxicon 52(2008) 428-439.

J.P. Zuliani, C.M. Fernandes, S.R. Zamuner, J.M. Gutiérrez, C.F. Teixeira,Inflammatory events induced by Lys-49 and Asp-49 phospholipases A2 isolated from Bothrops asper snake venom: role of catalytic activity, Toxicon 45(2005) 335-346. 
J.P. Zuliani, J.M. Gutiérrez, L.L. Casais e Silva, S. C. Sampaio, B. Lomonte, C.F.P. Teixeira, Activation of cellular functions in macrophages by venom secretory Asp-49 and Lys 49 phospholipases A(2), Toxicon 46 (2005) 523-532.

A.N. Hata, R.M. Breyer, Pharmacology and signaling of prostaglandin receptors: Multiple roles in inflammation and immune modulation, Pharmacol. Ther. 103 (2004) 147-166.

K. Kawahara, H. Hohjoh, T. Inazumi, S. Tsuchiya, Y. Sugimoto, Prostaglandin E2induced inflammation: Relevance of prostaglandin E receptors, Biochim. Biophys. Acta, 1851(2015) 414-421.

K. Omori,T. Kida, M. Hori, H. Ozaki, T. Murata, Multiple roles of the PGE2 -EP receptor signal in vascular permeability, Br. J. Pharmacol. 171(2014) 4879-4889.

V. Moreira, J.M. Gutiérrez, R.B. Amaral, B. Lomonte, E. Purgatto, C. Teixeira, A phospholipase $\mathrm{A}_{2}$ from Bothrops asper snake venom activates neutrophils in culture: expression of cyclooxygenase-2 and $\mathrm{PGE}_{2}$ biosynthesis, Toxicon 57(2011) 288-296.

Ruipérez V, Casas J, Balboa MA, Balsinde J. Group V phospholipase A2-derived lysophosphatidylcholine mediates cyclooxygenase-2 induction in lipopolysaccharide-stimulated macrophages. J Immunol. 179(2007):631-8.

V. Moreira, B. Lomonte, M.A. Vinolo, R. Curi, J.M. Gutiérrez, C. Teixeira, An Asp49 phospholipase A2 from snake venom induces cyclooxygenase-2 expression and prostaglandin E2 production via activation of NF- $\kappa \mathrm{B}, \mathrm{p} 38 \mathrm{MAPK}$, and PKC in macrophages, Mediators Inflamm. 2014 (2014) 105879.

A.C. Duchez, L.H. Boudreau, G.S. Naika, J. Bollinger, C. Belleannée, N. Cloutier, B. Laffont, R.E. Mendoza-Villarroel, T. Lévesque, E. Rollet-Labelle, M. Rousseau, I. Allaeys, J.J. Tremblay, P.E. Poubelle PE1, G. Lambeau, M. Pouliot, P. Provost, D. Soulet, M.H Gelb, E. Boilard, Platelet microparticles are internalized in neutrophils via the concerted activity of 12-lipoxygenase and secreted phospholipase A2-IIA, Proc. Natl. Acad. Sci. U S A 112(2015) E3564-E3573.

J. Shin, H. Cho, S.W. Hwang, J. Jung, C.Y. Shin, S.Y. Lee, S.H. Kim, M.G. Lee, Y.H. Choi, J. Kim, N.A. Haber, D.B. Reichling, S. Khasar, J.D. Levine, U. Oh, Bradykinin-12-lipoxygenase-VR1 signaling pathway for inflammatory hyperalgesia, Proc. Natl. Acad. Sci. U S A, 99(2002) 1015010155. 
Kim DY, Song HJ, Jeong JH, Suh JS, Sohn UD. Regulation of lysophosphatidic acid-induced COX-2 expression by ERK1/2 activation in cultured feline esophageal epithelial cells. Arch Pharm Res. 31(2008):1331-1338.

D.A. Taylor-Fishwick, J. Weaver, L. Glenn, N. Kuhn, G. Rai, A. Jadhav, A. Simeonov, A. Dudda, D. Schmoll, T.R. Holman, D.J. Maloney, J.L. Nadler, Selective inhibition of 12lipoxygenase protects islets and beta cells from inflammatory cytokine-mediated beta cell dysfunction, Diabetologia 58(2015) 549-557.

T. Hashimoto, M. Kihara, K. Yokoyama, T. Fujita, S. Kobayashi, K. Matsushita, K. Tamura, N. Hirawa, Y. Toya, S. Umemura, Lipoxygenase products regulate nitric oxide and inducible nitric oxide synthase production in interleukin-1beta stimulated vascular smooth muscle cells, Hypertens. Res. 26 (2003) 177-184.

S. Agarwal, C. Achari, D. Praveen, K.R. Roy, G.V. Reddy, P. Reddanna, Inhibition of 12-LOX and COX-2 reduces the proliferation of human epidermoid carcinoma cells (A431) by modulating the ERK and PI3K-Akt signalling pathways, Exp. Dermatol. 18(2009) 939-946.

X.Z. Ding, W.G. Tong, T.E. Adrian, 12-lipoxygenase metabolite 12(S)-HETE stimulates human pancreatic cancer cell proliferation via protein tyrosine phosphorylation and ERK activation, Int J Cancer. 94 (2001) 630-636.

N.P. McCabe, S.H. Selman, J. Jankun, Vascular endothelial growth factor production in human prostate cancer cells is stimulated by overexpression of platelet 12-lipoxygenase, Prostate, 66 (2006) 779-787.

R.A. Stockton, B.S. Jacobson, Modulation of cell-substrate adhesion by arachidonic acid: lipoxygenase regulates cell spreading and ERK-inducible cyclooxygenase regulates cell migration in NIH-3T3 fibroblasts, Mol. Biol. Cell, 12(2001) 1937-1956. 
Y. Wen Y, J. Gu, G.E. Vandenhoff, X. Liu, J.L. Nadler, Role of 12/15-lipoxygenase in the expression of MCP-1 in mouse macrophages, Am. J. Physiol. Heart Circ. Physiol, 294(2008) H1933-H1938.

K.J. Woo, J.H. Lim, S.I. Suh, Y.K. Kwon, S.W. Shin, S.C. Kim, Y.H. Choi, J.W. Park, T.K. Kwon, Differential inhibitory effects of baicalein and baicalin on LPS-induced cyclooxygenase-2 expression through inhibition of C/EBPbeta DNA-binding activity, Immunobiology 211(2006) 359-368.

X. Han, S. Chen, Y. Sun, J.L. Nadler, D. Bleich, Induction of cyclooxygenase-2 gene in pancreatic beta-cells by 12-lipoxygenase pathway product 12-hydroxyeicosatetraenoic acid, Mol. Endocrinol. 16 (2002) 2145-2154.

Z. G. Xu, S.L. Li, L. Lanting, Y.S. Kim, N. Shanmugam, M.A. Reddy, R. Natarajan, Relationship between 12/15-lipoxygenase and COX-2 in mesangial cells: potential role in diabetic nephropathy. Kidney Int. 69 (2006) 512-519.

M. Niknami, S. Vignarajan, M. Yao, S. Hua, P.K. Witting, Y. Kita, T. Shimizu, P. Sved, M.I. Patel, Q. Dong, Decrease in expression or activity of cytosolic phospholipase A2alpha increases cyclooxygenase-1 action: A cross-talk between key enzymes in arachidonic acid pathway in prostate cancer cells. Biochim. Biophys. Acta 1801(2010) 731-737.

K. Takayama, D. H. Mitchell, Z. Z. Din, P. Mukerjee, C. Li, D. L. Coleman, Monomeric Re lipopolysaccharide from Escherichia coli is more active than the aggregated form in the Limulus amebocyte lysate assay and in inducing Egr-1 mRNA in murine peritoneal macrophages, J. Biol. Chem. 269 (1994) 2241-2244.

B. Lomonte, J.M. Gutiérrez, A new muscle damaging toxin, myotoxin II, from the venom of the snake Bothrops asper (terciopelo), Toxicon 27 (1989) 725-733.

I.I. Kaiser, J.M. Gutierrez, D. Plummer, S.D. Aird, G.D. Odell, The amino acid sequence of a myotoxic phospholipase from the venom of Bothrops asper, Arch. Biochem. Biophys. 278 (1990) $319-25$. 
C.Y. Peng, S.L. Pan, Y.M. Huang, J.H Guh, Y.L. Chang, C.M. Teng, Baicalein attenuates intimal hyperplasia after rat carotid balloon injury through arresting cell-cycle progression and inhibiting ERK, Akt, and NF-kappaB activity in vascular smooth-muscle cells. Naunyn. Schmiedebergs Arch. Pharmacol. 378 (2008) 579-588.

Z. Qi, F. Yin, L. Lu, L. Shen, S. Qi, L. Lan, L. Luo, Z. Yin, Baicalein reduces lipopolysaccharideinduced inflammation via suppressing JAK/STATs activation and ROS production, Inflamm Res. $62(2013) 845-855$.

S. Nishimoto, E. Nishida, MAPK signalling: ERK5 versus ERK, EMBO Rep, 7(2006) 782-786.

Y. Rong, M. Baudry, Seizure activity results in a rapid induction of nuclear factor-kappa B in adult but not juvenile rat limbic structures. J Neurochem. 67(1996) 662-668.

M.M. Bradford, A rapid and sensitive method for the quantitation of microgram quantities of protein utilizing the principle of protein-dye binding. Anal. Biochem. 72 (1976) 248-254.

M.A. Vinolo, H.G. Rodrigues, E. Hatanaka, F.T. Sato, S.C. Sampaio, R. Curi, Suppressive effect of short-chain fatty acids on production of proinflammatory mediators by neutrophils. J. Nutr. Biochem. 22 (2011) 849-855.

V. Moreira, P.C.C. Souto, M.A.R Vinolo, B. Lomonte, J. M. Gutiérrez, R. Curi, C. Teixeira, A catalytically-inactive snake venom Lys49 phospholipase A2 homolog induces expression of cyclooxygenase-2 and production of prostaglandins through selected signaling pathways in macrophages, Eur. J. Pharmacol. 708(2013):68-79.

M.J. Coffey, B. Coles, M. Locke, A. Bermudez-Fajardo, P.C. Williams, G.E. Jarvis, V.B. O'donnell, Interactions of 12-lipoxygenase with phospholipase A2 isoforms following platelet activation through the glycoprotein VI collagen receptor, FEBS Lett. 576 (2004) 165-168.

T. Yoshimoto, Y. Takahashi. Arachidonate 12-lipoxygenases. Prostaglandins Other Lipid Mediat. 68-69 (2002) 245-262 
M.A. Balboa, E. Pérez, J. Balsinde, Amplification mechanisms of inflammation: paracrine stimulation of arachidonic acid mobilization by secreted phospholipase A2 is regulated by cytosolic phospholipase A2-derived hydroperoxyeicosatetraenoic acid, J. Immunol. 171 92003) 989-994.

M.K. Patricia, J.A. Kim, C.M. Harper, P.T. Shih, J.A. Berliner, R. Natarajan, J.L. Nadler, C.C. Hedrick, Lipoxygenase products increase monocyte adhesion to human aortic endothelial cells, Arterioscler Thromb. Vasc. Biol. 19(1999) 2615-2622.

Hughes-Fulford M, Chen Y, Tjandrawinata RR. Fatty acid regulates gene expression and growth of human prostate cancer PC-3 cells. Carcinogenesis. 22(2001):701-707.

K.B. Reilly, S. Srinivasan, M.E. Hatley, M.K. Patricia, J. Lannigan, D.T. Bolick, G. Vandenhoff, H. Pei, R. Natarajan, J.L. Nadler,C.C.Hedrick, 12/15-Lipoxygenase activity mediates inflammatory monocyte/endothelial interactions and atherosclerosis in vivo, J. Biol. Chem. 279 (2004) 94409450.

J. Faulkner, C. Pye, M. Al-Shabrawey, A.A. Elmarakby, Inhibition of 12/15-Lipoxygenase Reduces Renal Inflammation and Injury in Streptozotocin-Induced Diabetic Mice, J. Diabetes Metab. 6(2015). pii: 555.

Ohd JF, Wikström K, Sjölander A. Leukotrienes induce cell-survival signaling in intestinal epithelial cells. Gastroenterology. 119(2000):1007-1018.

Y. Wen, J. Gu, S.K. Chakrabarti, K. Aylor, J. Marshall, Y. Takahashi, T. Yoshimoto, J.L. Nadler. The role of 12/15-lipoxygenase in the expression of interleukin- 6 and tumor necrosis factor-alpha in macrophages, Endocrinology 148 (2007) 1313-1222.

S.K. Chakrabarti, B.K. Cole, Y. Wen, S.R. Keller, J.L. Nadler, 12/15-lipoxygenase products induce inflammation and impair insulin signaling in 3T3-L1 adipocytes. Obesity (Silver Spring) 17(2009) 1657-1663. 
C.K. Szekeres, K. Tang, M. Trikha, K.V Honn, Eicosanoid activation of extracellular signalregulated kinase1/2 in human epidermoid carcinoma cells, J. Biol. Chem. 275(2000): 38831-38841.

F.L. Chen, X.Z. Wang, J.Y. Li, J.P. Yu, C.Y. Huang, Z.X. Chen, 12-lipoxygenase induces apoptosis of human gastric cancer AGS cells via the ERK signal pathway, Dig. Dis. Sci. 53 (2008) 181-487.

Y. Wen, J. Gu, G.E. Vandenhoff, X. Liu, J.L. Nadler, Role of 12/15-lipoxygenase in the expression of MCP-1 in mouse macrophages, Am. J. Physiol. Heart Circ. Physiol. 294 (2008) H1933-H1938.

W.G. Tong, X.Z. Ding, R.C. Witt, T.E. Adrian, Lipoxygenase inhibitors attenuate growth of human pancreatic cancer xenografts and induce apoptosis through the mitochondrial pathway, Mol. Cancer Ther. 1 (2002) 929-935.

R. Yoshimura, K. Inoue, Y. Kawahito, M. Mitsuhashi, K. Tsuchida, M. Matsuyama, H. Sano, T. Nakatani. Expression of 12-lipoxygenase in human renal cell carcinoma and growth prevention by its inhibitor. Int. J. Mol. Med. 13 (2004) 44-46.

X.M. Xu XM,G.J. Yuan, J.J. Deng, H.T. Guo, M. Xiang, F. Yang, W. Ge, S.Y. Chen, Inhibition of 12-lipoxygenase reduces proliferation and induces apoptosis of hepatocellular carcinoma cells in vitro and in vivo, Hepatobiliary Pancreat. Dis. Int. 11(2012) 193-202.

J.F. Di Mari, J.I. Saada, R.C. Mifflin, J.D. Valentich, D.W. Powell, HETEs enhance IL-1-mediated COX-2 expression via augmentation of message stability in human colonic myofibroblasts, Am. J. Physiol. Gastrointest. Liver Physiol. 293 (2007) G719-728.

Ma K, Nunemaker CS, Wu R, Chakrabarti SK, Taylor-Fishwick DA, Nadler JL. 12-Lipoxygenase Products Reduce Insulin Secretion and \{beta\}-Cell Viability in Human Islets. J Clin Endocrinol Metab. 2010 Feb;95(2):887-93.

Wen Y, Gu J, Chakrabarti SK, Aylor K, Marshall J, Takahashi Y, Yoshimoto T, Nadler JL. The role of 12/15-lipoxygenase in the expression of interleukin- 6 and tumor necrosis factor-alpha in macrophages. Endocrinology. 2007 Mar;148(3):1313-22. 
I. Garcia-Verdugo, F. BenMohamed, S. Tattermusch, D. Leduc, G. Charpigny, M. Chignard, M. Ollero, L. Touqui, A role for 12R-lipoxygenase in MUC5AC expression by respiratory epithelial cells, Eur. Respir J. 40 (2012) 714-723.

R. Martín, C. Cordova, M.L. Nieto, Secreted phospholipase A2-IIA-induced a phenotype of activated microglia in BV-2 cells requires epidermal growth factor receptor transactivation and proHB-EGF shedding, J. Neuroinflammation 9 (2012) 154.

J.A. Yu, S. Kalatardi, J. Dohse, M.R. Sadaria, X. Meng, D.A. Fullerton, M.J. Weyant, Group IIa sPLA2 inhibition attenuates NF- $\kappa$ B activity and promotes apoptosis of lung cancer cells. Anticancer Res. 32 (2012) 3601-3607.

M. Hernández, S.L. Burillo, M.S. Crespo and M.L. Nieto, Secretory phospholipase A2 activates the cascade of mitogen-activated protein kinases and cytosolic phospholipase A2 in the human astrocytoma cell line 1321N1, J. Biol. Chem. 273 (1998) 606-612.

E. Leiguez, J.P. Zuliani, A.M. Cianciarullo, C.M. Fernandes, J.M. Gutiérrez, C. Teixeira, A group IIA-secreted phospholipase A2 from snake venom induces lipid body formation in macrophages: the roles of intracellular phospholipases A2 and distinct signaling pathways, J. Leukoc.

Biol. 90(2011) 155-166.

K.C. Giannotti, E. Leiguez, V. Moreira, N.G. Nascimento, B. Lomonte, J.M. Gutiérrez, R.L Melo, C. Teixeira, A Lys49 phospholipase A2, isolated from Bothrops asper snake venom, induces lipid droplet formation in macrophages which depends on distinct signaling pathways and the C-terminal region. Biomed Res Int. 2013 (2013)807982.

E. Kikawada, J.V. Bonventre, J.P. Arm, Group V secretory PLA2 regulates TLR2-dependent eicosanoid generation in mouse mast cells through amplification of ERK and cPLA2alpha activation. Blood. 110(2007) : 561-567.

C.C. Hedrick, M.D. Kim, R.D. Natarajan, J.L. Nadler. 12-Lipoxygenase products increase monocyte:endothelial interactions, Adv. Exp. Med. Biol.469 (1999) 455-460. 
M. Triggiani, F. Granata, A. Petraroli, S. Loffredo, A. Frattini, R.I. Staiano, G. Monaco, G. Marone, Inhibition of secretory phospholipase A2-induced cytokine production in human lung macrophages by budesonide. Int Arch Allergy Immunol.150(2009) 144-155.

W.K. Han, A. Sapirstein, C.C. Hung, A. Alessandrini, J.V. Bonventre, Cross-talk between cytosolic phospholipase A2 alpha (cPLA2 alpha) and secretory phospholipase A2 (sPLA2) in hydrogen peroxide-induced arachidonic acid release in murine mesangial cells: sPLA2 regulates cPLA2 alpha activity that is responsible for arachidonic acid release, J. Biol. Chem. 278(2003) 24153-24163.

A.A. Carmo, B.R. Costa, J.P. Vago, L.C. de Oliveira, L.P. Tavares, C.R. Nogueira, A.L. Ribeiro, C.C. Garcia, A.S. Barbosa, B.S. Brasil, L.M. Dusse, L.S. Barcelos, C.A. Bonjardim, M.M. Teixeira , L.P. Sousa, Plasmin induces in vivo monocyte recruitment through protease-activated receptor-1-, MEK/ERK-, and CCR2-mediated signaling. J. Immunol. 193(2014) 3654-63.

Hernández M, Martín R, García-Cubillas MD, Maeso-Hernández P, Nieto ML.

Secreted PLA2 induces proliferation in astrocytoma through the EGF receptor: another inflammation-cancer link. Neuro Oncol. 2010 Oct;12(10):1014-23.

Y.C. Hseu, K.J. Senthil Kumar, C.S. Chen, H.J. Cho, S.W. Lin, P.C. Shen, C.W. Lin, F.J. Lu, H.L. Yang, Humic acid in drinking well water induces inflammation through reactive oxygen species generation and activation of nuclear factor- $\mathrm{kB} /$ activator protein- 1 signaling pathways: a possible role in atherosclerosis, Toxicol. Appl. Pharmacol. 274(2014) 249-262.

A.G. Eliopoulos, C.D. Dumitru, C.C. Wang, J. Cho, P.N. Tsichlis, Induction of COX-2 by LPS in macrophages is regulated by Tpl2-dependent CREB activation signals. EMBO J. 21(2002) 48314840.

T. Ueno, K. Fujimori, Novel suppression mechanism operating in early phase of adipogenesis by positive feedback loop for enhancement of cyclooxygenase- 2 expression through prostaglandin F2 $\alpha$ receptor mediated activation of MEK/ERK-CREB cascade, FEBS J. 278(2011) 2901-2912. 

